\title{
Teaching Practice for Control Engineering Fundamental Based on Solving Complicated Mechanical Engineering Problems
}

\author{
Liping $\mathrm{Xu}^{1,}$, Liujin Cai ${ }^{1, b^{*}}$ and Yanbin Cui ${ }^{1, c}$ \\ ${ }^{1}$ School of Mechatronic Engineering, Henan University of Science and Technology, Luoyang, \\ 471003, China \\ axlpzz@163.com, byycailj@163.com, ccyb1378396@163.com \\ *The corresponding author
}

Keywords: Engineering education accreditation; Control engineering fundamental; Teaching practice; Complicated mechanical engineering problems; Effect assessment

\begin{abstract}
In order to meet the requirements of engineering education accreditation, aiming at the important basic course of Control Engineering Fundamental, a teaching model is put forward, which combine with the case teaching, multimedia, MATLAB professional software. It enables students to have a deep understanding of theoretical knowledge in this teaching practice model, and their ability of using knowledge to analyze and solve complicate problems in mechanical engineering field is improved. So it proves the feasibility of the teaching mode.
\end{abstract}

\section{Introduction}

Control Engineering Fundamental is a major basic discipline of mechanical design and manufacturing and automation[1]. This course introduces the classical control theory and the two aspects of knowledge including time domain and frequency domain mainly. It focuses on the analysis and design of control system, and it can help students lay a solid foundation for learning other professional course. This course's purpose is to train students to master the scientific method and improve the ability to analyze and solve complex problems in mechanical engineering. But in the teaching, the attendance rate is lower, students also only listen to lessons and cannot write homework, even failing the exam. Eventually students do not have the ability to solve complex problems in mechanical engineering. Obviously, the traditional teaching model does not adapt to the teaching demand of the information society on Control Engineering Fundamental. At the same time, it is inconsistent with the spirit of engineering education accreditation in university. The engineering education accreditation's object is to improve the quality of education and strengthen professional knowledge and cultivate a group of students who can solve the complicated mechanical engineering problems. Therefore, the exploration of teaching practice of Control Engineering Fundamental, improving teaching quality and learning efficiency is the urgent requirement of teachers and students[2]. The so-called complicated mechanical engineering problems must have the following characteristics:

(1)The problems can be solved through analyzing and using the deep engineering principle.

(2)The problems involve various technology, engineering and other factors, which may conflict with each other.

(3)The problems can be solved through establishing a suitable abstract model, it reflects the creative in the process of model .

(4)The problems cannot be completely resolved by common methods.

(5)Factors involved in the problems may not be fully included the standards and norms of professionals engineering practice.

(6)Related to the interests of the parties is not completely consistent.

(7)The problems have a high degree of comprehensiveness, including a number of interrelated sub problems. 


\section{Exploration on Teaching Practice}

Case Teaching for Engineering Problems. During the undergraduate teaching, the teaching theory of Control Engineering Fundamental is not too deep. A number of effective control cases in engineering practice should be increased to the classroom, namely case teaching. In fact, as long as the undergraduates master the basic knowledge of these control systems and avoid pursuing the integrity of the theoretical system, with focusing on practical engineering. By listing a large number of typical examples, such as iron and steel metallurgy system, control system of industrial robots, CNC turning control system and so on. These can improve the enthusiasm of students and enhance the learning enthusiasm, so it can achieve better teaching effect[1,3].

In learning Laplace transform and transfer function, students generally find it difficult to understand and lose interest in learning finally, which lead to poor basic course learning and worse professional foundation lessons. We can adopt case teaching in the studying and turn the classroom to Lathe laboratory, because we can see concrete object. As shown in Fig. 1 it is a system of turning lathe. Cutting force caused by actual cutting depth (assuming $u$ ), which act on the tool and machine tool. Then it may cause the deformation of tool, machine tool and workpiece. These can be converted to the lathe saddle and look as the displacement generated by lathe saddle. The deformation feedback to cause the change of cutting depth, so that workpiece, tool and machine tool form a closed loop system[4]. When the nominal cutting depth is taken as input and the turret deformation is taken as output, the transfer function of the turning process can be deduced as follows.

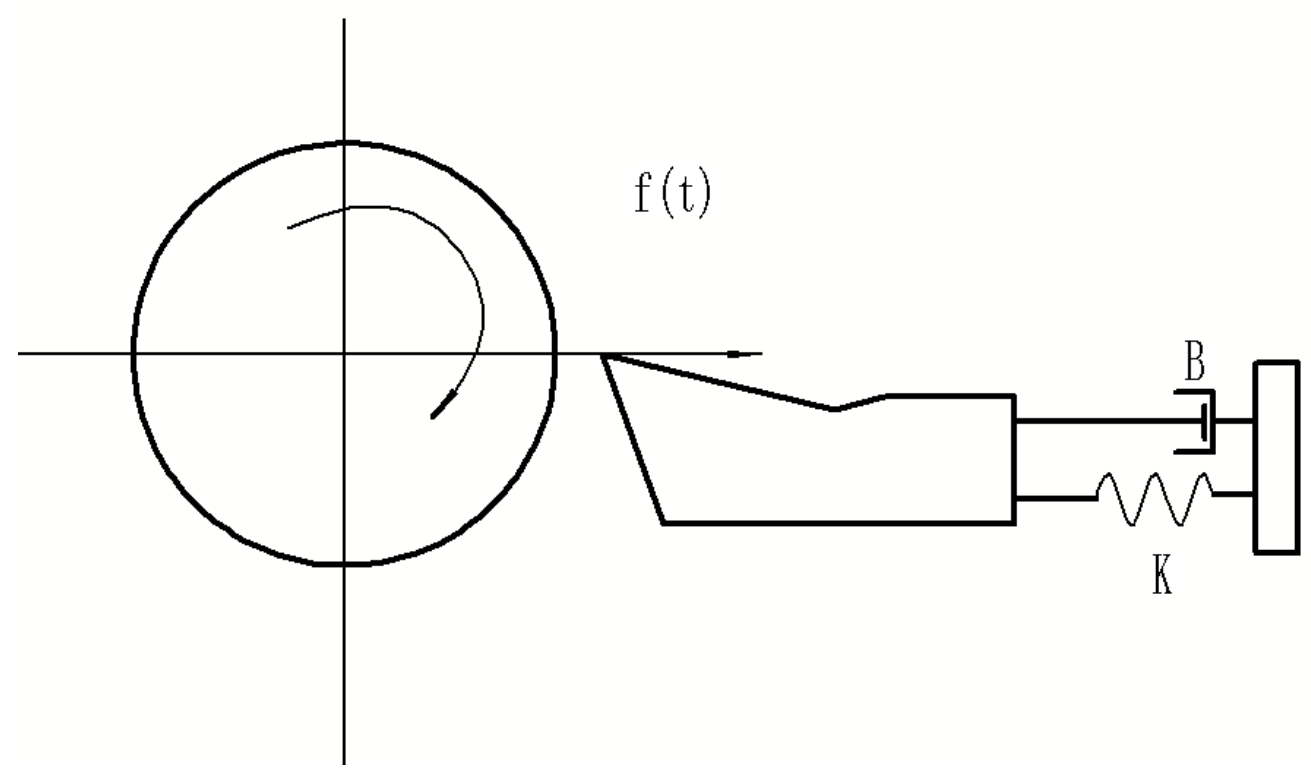

Figure 1. schematic diagram of turning process

Actual cutting depth

$u=u_{i}-x_{0}$

Laplace transform

$$
U(\mathrm{~s})=U_{i}(\mathrm{~s})-X_{0}(\mathrm{~s})
$$

According to the cutting force dynamic equation, the cutting force $f(t)$ caused by the actual cutting displacement $u$ is 


$$
f(t)=K_{c} u(t)+B_{C} \frac{d u(t)}{d t}
$$

In the Eq.3, $K_{c}$ coefficient of cutting process, it indicates the ratio of the cutting force to the resection; $B_{c}$ cutting damping coefficient, $\frac{\mathrm{d} u(t)}{d t}$ it indicates the ratio of the corresponding cutting force to the change rate of resection. Laplace transform is used to the formula, so the transfer function between cutting depth and cutting force is

$$
G_{C}(s)=\frac{F(\mathrm{~s})}{U(s)}=K_{c}(T s+1)
$$

Time constant $T=\frac{B_{\mathrm{c}}}{K_{c}}$.

Lathe saddle can be abstracted as a mass spring damping system with external force acting on mass. So the transfer function is

$$
G_{m}(s)=\frac{X_{0}(\mathrm{~s})}{F(s)}=\frac{1}{m s^{2}+B s+K}
$$

In the Eq.5 $F(\mathrm{~s})$ is input and $X_{0}(s)$ is output.

By case teaching of turning control system, students' learning enthusiasm and optimism is greatly improved. They understand Laplace transform and transfer function more clearly than before. Besides, teacher is not tired and students feel relaxed when they are in class. So it make students learn from passive to active truly[4,5].

Modern Teaching Tool Used to Solve Engineering Problems. According to the characteristics of control engineering fundamental, such as abstract content, complex calculation, huge drawing quantity and complicated system principle block diagram and so on[5]. It is difficult for students to understand by using the traditional teaching method. But the multimedia and MATLAB software tools are introduced into the teaching activities, we can achieve twice the result with half the effort. Teachers in the classroom should use MATLAB tools skillfully, then let students practice step by step through multimedia display. Students' homework should be finished by MATLAB tools proactively[6,7]. Teachers also make multimedia courseware and material library used in class. The material library will include engineering examples, illustrations, examples and exercises. These will play a better role in the classroom, which not only save the teaching time, but also make the content simple and intuitive. So the learning effect of students will be better. We can quickly draw the diagram of time domain and frequency domain and Nyquist by using MATLAB software to solve the system response. Beyond that, the interface of simulation system is very vivid based on Simulink module, we can be arbitrary to control the effect of the design. So that students can understand and accept what they learn easily[8]. As shown in Fig. 2 and Fig. 3, we can see Simulink model and unit step response curve of mechanical moving system. 


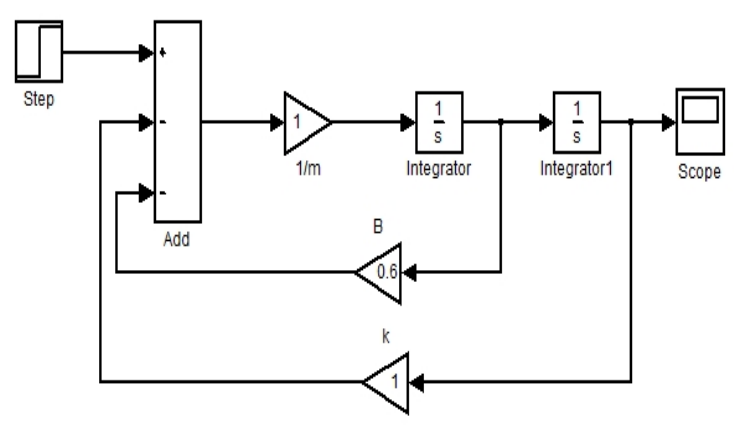

Figure 2. Simulink model of mechanical moving system

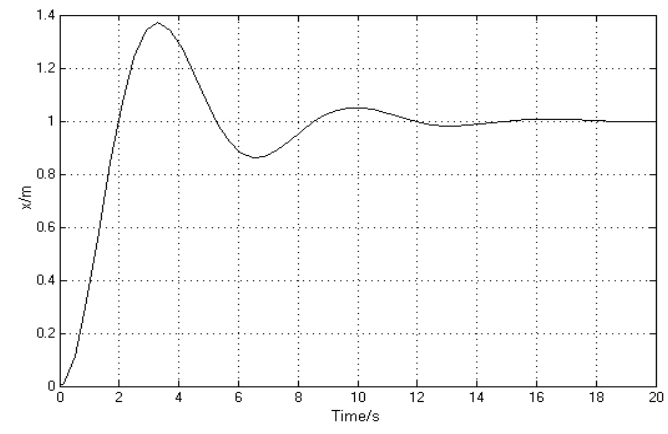

Figure 3. Unit step response curve of mechanical moving system

\section{Comparison of Teaching Practice Effect}

The implementation of control engineering teaching practice for two years, teachers are in charge of the employment service who visited the Pearl River Delta, Yangtze River Delta area, Jiaodong Peninsula, the Beijing-Tianjin region, northwest and central China, to carry out extensive research activities. At the same time, teachers in college invited employers to participate in school-enterprise activities repeatedly[8,9]. Through questionnaire survey on the graduates quality and contact with employers extensively, it can learn about employers' overall evaluation of mechanical graduates as shown in Table 1.

A: Comprehensive quality and solid foundation knowledge. Employers believe that the overall quality of our college graduates is "very strong" or "stronger" accounted for $92.2 \%$, and the theoretical basis is "very solid" or "solider" accounted for $93.8 \%$.

B: Strong sense of responsibility, dedication, good working attitude, well working. $89 \%$ of employers believe that our graduates' work responsibility is "very strong" or "stronger", $71.9 \%$ employers think graduates" work ability is "competent" or "more competent".

C: Work fast, strong practical ability and adaptability and innovative spirit, the ability to understand and receive new knowledge is stronger than before. They believe our graduates' professional knowledge can meet the need of the work accounted for $60.9 \%$, the "very strong" or "stronger" innovative spirit is accounted for $73.4 \%, 92.2 \%$ employers think that our graduates can solve practical problems "independently" or "under the guidance", 59.4\% employers think that "our graduates adapt working conditions quickly".

D: Strong team work spirit, being able to get along well with colleagues and leaders. The overall impression of our college graduates is "excellent" or "good" accounted for 93.7\%. Employers think that the team awareness and cooperation ability is "very strong" or "stronger" accounted for $82.8 \%$.

\section{Conclusions}

Control engineering fundamental is the basic course of mechanical specialty in our college, we combine the teaching practice of case, multimedia and MATLAB professional software, which has achieved preliminary teaching effect[9]: Teachers is no longer just emphasize the theoretical study but how to apply knowledge, so the burden of students is lighter and the organization of teacher in class is better than before; the introduction of MATLAB and multimedia in class to improve learning interest and lay a solid foundation for studying professional course. We can choose the appropriate technology, resources, modern engineering tools and information technology tools to solve complex mechanical engineering problems; Using case teaching can make students realize the current developing situation and trend of mechanical industry; mathematics, natural science, 
professional knowledge of control engineering fundamental is used to solve complicated mechanical engineering problems by students, which meet requirements of Engineering Education Professional Certification[10].

Table 1 The survey of employers' satisfaction with graduates in our college

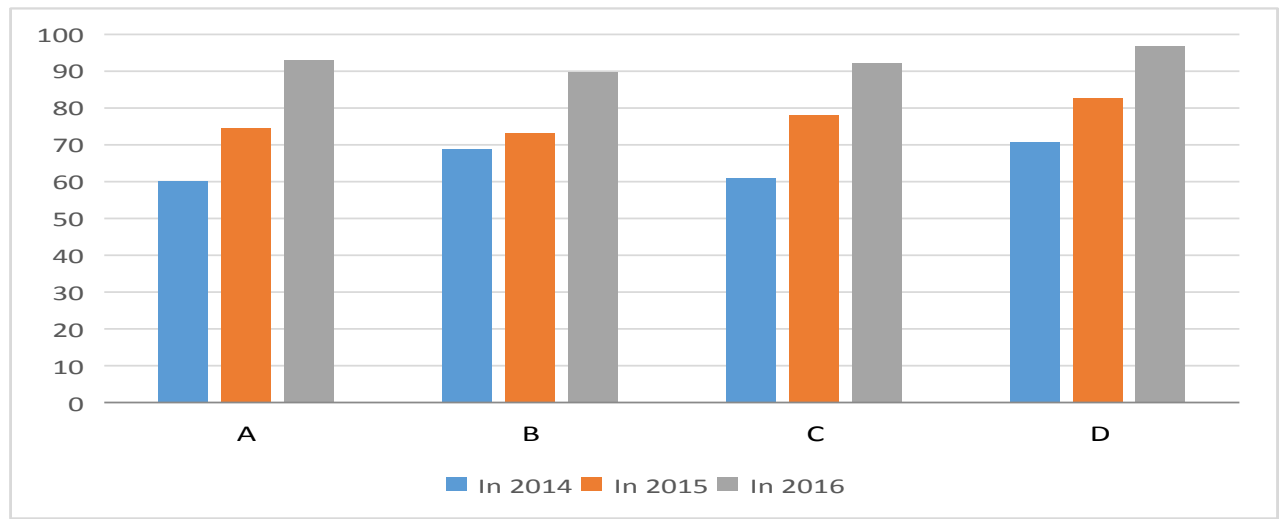

\section{Acknowledgements}

The authors gratefully acknowledge the superior course of Henan University of Science and Technology for financial support of this research work. (No. 2012N-007)

\section{References}

[1] Jianxi Yang, Liping Xu: Control Engineering Fundamental (Science Press, BeiJing and 2008), P.78-79. (In Chinese)

[2] Wei Wang, Ai-ming Shen: Journal of AnHui Normal University (Natural Science Edtition), Vol. 302007 No.2, P.139-141. (In Chinese)

[3] Lei Zhang, Shuchen Wang and Jianhua Zhang: Journal of Higher Education, Vol. 92016 No.9, P.127-128. (In Chinese)

[4] Jun Feng. University Education, 2015,P.161-162. (In Chinese )

[5] Zhuanzhe Zhao, Dezhang Xu and Jiufang Pei: Science and Technology Innovation Herald, 2016 No.9, P.200-202. (In Chinese)

[6] Huan Zhang: China Electric Power Education, 2014 No.21, P.70-71. (In Chinese )

[7] Wei Wang, Ai-ming Shen, Shunying Lin, Ya Chen and Dianjun Wang: Journal of Anhui Normal University(Natural Science Edition), Vol. 342011 No.2, P.142-144. (In Chinese)

[8] Dayong Li, Haipeng Lin and Hongyan Zhang: China Electric Power Education, 2013 No.29, P. 51-72. (In Chinese)

[9] Wenxiu Liu, Wei Guo: Journal of Shaoguan University, Vol.10 2016 No.36, P.100-103. (In Chinese )

[10] Xianhui Zhou: HIGHER EDUCATION FORUM, 2010 No.1, P.81-84.(In Chinese) 